\title{
Intermittent clobazam for catamenial epilepsy: tolerance avoided
}

\author{
MORGAN FEELY, JOHN GIBSON* \\ From the University Department of Medicine and Department of Neurology, Leeds General Infirmary and \\ Department of Neurology, St James's University Hospital, Leeds, UK
}

SUMMARY Clobazam, 20 or $30 \mathrm{mg} /$ day was given for 10 days around menstruation in successive menstrual cycles to 13 women who had responded favourably to this drug in an earlier short-term placebo controlled cross-over study. Three patients have been successfully treated, with complete freedom from seizures around menstruation, for 3-31/2 years and two others responded favourably until pregnancy made treatment inappropriate. A further four patients did well during a shorter period (6-13 months) of follow-up. An increase in seizures between periods of clobazam therapy was observed in three patients, and led to the withdrawal of this drug in two of them. However, tolerance to the antiepileptic effect of clobazam was not observed in any patient, even though nine were treated for 1 year or more. In only once case was it necessary to discontinue treatment because of sedative side effects.

The $1-5$, benzodiazepine clobazam is a potent anticonvulsant ${ }^{1-3}$ but during chronic treatment many patients develop tolerance to its antiepileptic effect. ${ }^{4}$ After reading of the findings of Gastaut and Low $^{1}$ in their uncontrolled study of clobazam in chronic epilepsy, we decided to try clobazam to prevent the regular exacerbations which, even during conventional therapy, many epileptic women experience around the time of menstruation. We were able also to use catamenial epilepsy as a model in which we made a rapid evaluation of the antiepileptic effect of clobazam in a placebo controlled cross over study. ${ }^{2}$ This paper reports our long-term experience of using intermittent clobazam therapy in catamenial epilepsy. While this latter investigation took the form of an open study we have confined our observations to patients in whom we had been able to demonstrate clearly the efficacy of clobazam during the initial placebo controlled investigation. We hoped that by confining treatment to a short time (10 days) around each menstrual period we could avoid the development of tolerance to the antiepileptic effect of clobazam.

Address for reprint requests: Dr M Feely, University Department of Medicine, The General Infirmary, Leeds LS1 3EX, UK.

${ }^{*}$ Present address: Department of Neurology, Plymouth General Hospital, Plymouth PL4 7JJ, UK.

Received 13 April 1984. Accepted 11 June 1984

\section{Patients and methods of assessment}

Details of our initial placebo-controlled cross-over study have already been published. ${ }^{2}$ Doses of $20 \mathrm{mg}$, and in some cases $30 \mathrm{mg}$, per day, given for 10 days around the time of menstruation, were compared with placebo and the results evaluated by preference in a sequential procedure. The basis of preference was either complete suppression of seizures (patients usually having $<4$ fits in a ten-day period around menstruation) or a greater than $50 \%$ reduction in seizures (in patients usually having four or more fits in 10 days around menstruation) by one treatment and not the other. In 14 of 18 patients who took both treatments clobazam was superior to placebo and in four patients no preference was established. Of these 14 patients eight (table 2, Nos 1-8) responded to clobazam $20 \mathrm{mg}$ but not placebo. Three patients (Nos 9-11) responded to both treatments initially but when the treatments were repeated only clobazam $(20 \mathrm{mg})$ prevented the usual cluster of seizures around the time of menstruation. In three other patients (Nos 12-14) clobazam $30 \mathrm{mg} /$ day completely prevented or greatly reduced seizures associated with menstruation when a dose of $20 \mathrm{mg} /$ day proved ineffective for this purpose. Entry to this sequential trial, which used a restricted plan with $2 \alpha=0.01,1-\beta=0.95, \theta_{1}=0.85$ and $\mathrm{N}$ $=33$, was closed when results were significant at the $1 \%$ level. Subsequently, when other patients already under treatment reported, further preferences, all for clobazam, were obtained. In most of the patients treated clobazam completely prevented seizures and toxic effects were of low frequency and severity.

We have further studied the efficacy of intermittent clobazam therapy, given around the time of menstruation 
Table 1 Summary of the patients' seizure types and other drug therapy

\begin{tabular}{lll}
\hline Case No & Seizure types & Other drug \\
\hline 1 & Ab; GM & VPA \\
2 & CP; GM & CBZ \\
3 & CP; GM & CBZ \\
4 & CP; GM & CBZ; PHT \\
5 & CP; GM & CBZ \\
6 & CP; GM & CBZ; PHT \\
7 & Cpd; GM & CBZ; PHT \\
8 & CP; GM & CBZ; PR \\
9 & CP; GM & CBZ \\
10 & CP; GM & CBZ \\
11 & GM & PB; PHT \\
12 & CP; GM & CBZ \\
13 & CP; GM & CBZ; VPA: PR \\
14 & Cpd; GM & CBZ; VPA \\
\hline
\end{tabular}

Seizure types: $\mathbf{G M}=$ grand-mal; $\mathbf{C P}=$ complex partial seizures; $\mathrm{Ab}$ = petit-mal absences; $\mathrm{Cpd}=$ partial seizures, compound forms. Other drugs: $\mathbf{C B Z}=$ carbamazepine; $\mathbf{P B}=$ phenobarbitone; $\mathbf{P H T}$ $=$ phenytoin $; \mathbf{P R}=$ primidone; $\mathrm{VPA}=$ valproate

only, in 13 of these women. In the case of the 14th patient who responded to clobazam it was apparent by the end of the cross-over study that, because of frequent grand mal seizures between her periods, a radical change in overall treatment was more appropriate.

Our subjects were women with intractable epilepsy in whom the association of seizures with menstruation was both pronounced and consistent. In all of them, before entry to the cross-over study, it was possible to deliniate a ten-day period, starting no earlier than 7 days and no later than 2 days before the menstrual flow, during which several seizures had occurred in each cycle in the preceeding six months. In both the initial cross-over study and the long term study, this ten day target period for treatment was timed for each patient so that treatment would begin two to four days before the time during which the exacerbation of epilepsy usually occurred. Subject to the unforeseeable variation of her menstrual cycle, each woman was thus scheduled to start treatment in every cycle at the same time in relation to both the onset of menstruation and the expected seizures. In the event that either menstruation or the expected cluster of seizures began sooner than anticipated the patient started treatment immediately. All subjects took conventional anticonvulsant therapy (table 1), without change or interruption, throughout the study.

\section{Results}

The results of treatment are summarised in table 2 . Four patients (Nos 5, 6, 10,11) were treated at St James's Hospital and when one of us (JG) left Leeds it was not possible to follow them further. They were, however, followed for 6-13 months while taking clobazam $(20 \mathrm{mg} /$ day) just before and during menstruation. During that time one of them had a single fit while taking clobazam. In another of these patients it appeared that, after 12 months treatment, there had been some increase in seizure between periods of clobazam therapy. The other nine patients were treated at Leeds General Infirmary and it is in these patients that it is most easy to assess the results of long-term treatment with clobazam. The use of clobazam around the time of menstruation appeared to be a very effective long-term treatment for catamenial epilepsy in five of these nine patients. Two of these patients (Nos 2 and 4) took clobazam until they became pregnant. One never had any seizures and the other had just one seizure while taking clobazam. Three other patients are still on treatment after 3-31/2 years and none of them have had seizures while taking clobazam. In all of these cases not only were seizures around mens-

Table 2 Results of treatment

\begin{tabular}{|c|c|c|c|c|c|c|}
\hline \multirow{2}{*}{ Case No } & \multicolumn{3}{|c|}{ Cross-over study } & \multicolumn{3}{|l|}{ Intermittent therapy } \\
\hline & $\begin{array}{l}\text { seizures per } \\
\text { Before } \\
\text { treatment }\end{array}$ & $\begin{array}{l}\text { day period } \\
\text { On clobazam }\end{array}$ & On placebo & $\begin{array}{l}\text { Duration and } \\
\text { outcome of treatment }\end{array}$ & $\begin{array}{l}\text { Seizures while taking } \\
\text { clobazam }\end{array}$ & $\begin{array}{l}\text { Increase in seizures } \\
\text { between periods }\end{array}$ \\
\hline $\begin{array}{l}1 \\
2 \\
3 \\
4 \\
5 \\
6 \\
7\end{array}$ & $\begin{array}{l}40-100 \dagger \\
2-3 \\
5-12 \\
2-5 \\
2-3 \\
2 \\
6-8\end{array}$ & $\begin{array}{r}20 \\
0 \\
0 \\
0 \\
0 \\
0 \\
0\end{array}$ & $\begin{array}{c}50 \dagger \\
2 \\
7 \\
3 \\
3 \\
2 \\
6\end{array}$ & $\begin{array}{r}5 \text { months (D) } \\
12 \text { months (B) } \\
31 \text { ) years (A) } \\
15 \text { months (B) } \\
6 \text { months (X) } \\
12 \text { months (X) } \\
2 \text { months (E) }\end{array}$ & \multirow{2}{*}{$\begin{array}{l}20 \dagger(\text { per period) } \\
\text { None } \\
\text { None } \\
1 \text { (total) } \\
\text { None } \\
\text { None } \\
\text { On } 20 \mathrm{mg}-\text {-none } \\
\text { On } 10 \mathrm{mg}-6 \\
\text { None } \\
\text { None } \\
1 \text { (total) } \\
\text { None } \\
\text { None } \\
\text { None } \\
\text { - }\end{array}$} & $\begin{array}{l}\text { No } \\
\text { No } \\
\text { No } \\
\text { No } \\
\text { No } \\
\text { Yes } \\
\text { No }\end{array}$ \\
\hline $\begin{array}{r}8 \\
9 \\
10 \\
11 \\
12 \\
13 \\
14\end{array}$ & $\begin{array}{l}4-8 \\
5-7 \\
2-3 \\
2-4 \\
2-4 \\
2-4 \\
4-8\end{array}$ & $\begin{array}{l}0 \\
0(0)^{*} \\
0(0)^{*} \\
0(0)^{*} \\
1(0)^{*} \\
2(0)^{*} \\
4(1)^{*}\end{array}$ & $\begin{array}{l}5 \\
1(3)^{*} \\
0(5)^{*} \\
0(3)^{*} \\
3(4)^{*} \\
2(1)^{*} \\
3(8)^{*}\end{array}$ & $\begin{array}{l}4 \text { months }(C) \\
3 \text { years }(A) \\
12 \text { months }(X) \\
13 \text { months (X) } \\
3 \text { years }(A) \\
12 \text { months }(C) \\
-(D)\end{array}$ & & $\begin{array}{l}\text { Yes } \\
\text { No } \\
\text { No } \\
\text { No } \\
\text { No } \\
\text { Yes } \\
-\end{array}$ \\
\hline
\end{tabular}

Outcome of long-term treatment: (A) still using clobazam, (B) successful treatment until pregnancy, (C) clobazam stopped when seizures between periods increased, (D) treatment changed because of poor overall control, (E) clobazam stopped because of sedative effects, (X) not determined-insufficient follow-up (see results).

*numbers in parenthesis refer to a second course of treatment. †approximately. 
truation prevented by clobazam but overall seizure frequency was much reduced.

In one patient (No 7) clobazam $20 \mathrm{mg} /$ day, which prevented seizures, proved unacceptably sedative, and clobazam $10 \mathrm{mg} /$ day was ineffective. In two other patients (Nos 8 and 13) the reduction in seizures at menstruation was accompanied by an, approximately equal, increase in seizures between periods. The timing of these fits was variable and, based on two cases, it is not possible to say whether or not some may have been precipitated by clobazam withdrawal. One patient with frequent absences (No 1) had only a partial response to clobazam and continued to have some sporadic grand mal fits between periods. After 5 months her other drug therapy was changed, with considerable benefit, and clobazam was discontinued. On a few occasions, because of the normal variations of the menstrual cycle, patients took the full 10 day course of clobazam before menstruation began. In most such instances they still had fewer seizures (if any) at menstruation than was usual before treatment.

\section{Discussion}

The term "catamenial epilepsy" is used to describe the association of seizure exacerbations with menstruation. It appears that many women have an increase in seizures just before and during the menses. ${ }^{56}$ Normally such women are give conventional antiepileptic therapy using drugs appropriate to their seizure types. Despite such therapy some women continue to have regular exacerbations of their epilepsy around the time of the menses. To date, treatment for this situation, using hormones, diuretics or increased doses of antiepileptics, has been largely unsatisfactory. ${ }^{6}$

We believe that clobazam represents a valuable treatment for catamenial epilepsy. After 3-31/2 years therapy three of our 13 patients are still taking it to good effect and two others only stopped because they became pregnant. While in some other cases the duration of follow-up was inadequate to allow any firm conclusion to be drawn about the efficacy of long-term treatment the patients benefitted for many months (at least). Although it was not a prerequisite for entry to the trial, all of the women we treated had epilepsy for ten years or more and most of them had complex partial seizures which were sometimes secondarily generalised. Several drugs had been tried in all of them and despite conventional antiepileptic therapy they continued to have seizures around the time of menstruation. We believe that any therapy which proved effective in the long term in an appreciable proportion of such patients is worthwhile. We must, however, point out that we chose as our subjects women in whom the association of seizures with menstruation was both marked and consistent. Before treatment they were having two-thirds or more of all their fits around menstruation. The benefits of using clobazam might be less in women in whom the association of seizures with menstruation was less marked and/or less consistent.

Tolerance to the antiepileptic effect of clobazam has recently been demonstrated in an animal model ${ }^{5}$ and undoubtedly it is a problem in man. It is somewhat more difficult to say exactly how often and how quickly tolerance develops. Allen et al, ${ }^{3}$ whose patients were only treated for 9 weeks, did not see tolerance but Gastaut and Low ${ }^{1}$ reported tolerance developing after only a few weeks or months in one third of their patients. One of the authors has studied the first 10 patients with severe epilepsy ( $>$ fit/week) to whom he gave clobazam as continuous, rather than intermittent, therapy. Seven of them responded initially and in five all seizures ceased for at least one month. However, on long-term followup it was found that within 6-7 months all seven patients had relapsed. ${ }^{4}$

On comparing the outcome of long-term intermittent therapy to the results of long-term continuous treatment with clobazam we feel that it is safe to conclude that tolerance does not develop while treatment is confined to 10 days in each month. Taken with the observation that patients who have developed tolerance during continuous therapy may respond again after a "holiday" from clobazam' this finding seems to point to a need for studies of crosstolerance between clobazam and other anticonvulsants, both benzodiazepines and nonbenzodiazepines. Like other investigators, ' we have seen patients with otherwise refractory epilepsy who responded favourably to clobazam during several periods of treatment (each lasting weeks or months) punctuated by "holidays" from the drug. However, in the case of one of the patients (mentioned above) who developed tolerance during continuous clobazam therapy the subsequent withdrawal of clobazam appeared to precipitate an episode of status epilepticus. It seems that when tolerance has developed an increase in seizure frequency may still follow clobazam withdrawal. Excluding catamenial epilepsy, where the period of treatment is short enough to avoid tolerance, this greatly limits the usefulness of "interrupted therapy". The identification of other drugs which were as effective in the short-term as clobazam and which did not produce cross-tolerance with clobazam could lead to a new approach to refractory epilepsy. 


\section{References}

' Gastaut J, Low MD. Antiepileptic properties of clobazam, a 1-5 benzodiazepine, in man. Epilepsia 1979;20:437-46.

${ }^{2}$ Feely M, Calvert R, Gibson J. Clobazam in catamenial epilepsy: a model for evaluating anticonvulsants. Lancet 1982;ii:71-73.

${ }^{3}$ Allen JW, Oxley J, Robertson MM, Trimble MR, Richens A, Jawad SSM. Clobazam as adjunctive treatment in refractory epilepsy. $\mathrm{Br} \mathrm{Med} J$ 1983;286: $1246-47$.
${ }^{4}$ Feely M. Long-term use of clobazam in refractory epilepsy. Ir J Med Sci 1983;152:83.

${ }^{5}$ Gowers WR. Epilepsy and other chronic convulsive diseases: their causes, symptoms and treatment. American Academy of Neurology reprint series, Vol 1. New York: Dover Publications Inc, 1964:164.

- Newmark ME, Penry JK. Catamenial epilepsy: a review. Epilepsia 1980;21:281-300.

${ }^{7}$ Gent JP, Haigh JRM. Development of tolerance to the anticonyulsant effects of clobazam. Eur J Pharmacol 1983;94:155-8. 